\title{
First report of leaf spot of Sarcococca saligna caused by Paraconiothyrium brasiliense in Pakistan
}

\author{
Najam ul Sehar Afshan ${ }^{1}$ (D) Umaima Mujahid ${ }^{1} \cdot$ Aamna Ishaq $^{2} \cdot$ Abdul Nasir Khalid $^{1}$
}

Received: 15 April 2019 / Accepted: 5 November 2019 / Published online: 14 November 2019

(C) Società Italiana di Patologia Vegetale (S.I.Pa.V.) 2019

Keywords Khanspur $\cdot$ Leaf spot $\cdot$ Pakistan $\cdot$ Sarcococca

Sarcococca saligna (D. Don) Müll. Arg. is a common shrub, traditionally used in pharmaceuticals in Pakistan. Leaf, bark and root of plant are used in country because of its cardiosuppressant, vasodilator and tracheal relaxant properties (Ghayur and Gilani 2006). In October 2018, infected leaves of $S$. saligna plants were collected from fields of Khanspur (Pakistan). Approximately 15 to $35 \%$ of plants exhibited symptoms of varying shades of brown spots on leaves in oblong streaks with necrotic lesions. Infected leaves $(5 \mathrm{~mm}$ in length) were surface sterilized with $2 \%$ sodium hypochlorite, rinsed with sterile distilled water, air dried and cultivated on Malt Extract Agar (MEA) at $27{ }^{\circ} \mathrm{C}, 4-5$ days after inoculation. Colonies on MEA were white with pointed, filamentous margins, oblong with aerial mycelium; reverse light orange-yellow, but with tawny zone around centre; frequent complex conidiomata developing from 7 to 11 days onwards, were visible as scattered black dots on both sides of plate, later converting into sub-marginal ring. Hyphae were dark walled, conidia prominent, ellipsoid or cylindrical, colourless to olive $(3.5-4.5 \times 2-2.3 \mu \mathrm{m})$. The pathogen was identified as Paraconiothyrium brasiliense Verkley, based on morphological characteristics. The nrDNA of internal transcribed spacer (ITS1-5.8S-ITS2) region was amplified using primers ITS1F (forward) /ITS4 (reverse) (White et al. 1990). The obtained sequence (MK779925) has 99\% similarity

Electronic supplementary material The online version of this article (https://doi.org/10.1007/s42161-019-00449-6) contains supplementary material, which is available to authorized users.

Najam ul Sehar Afshan

pakrust@gmail.com; najamulsehar.hons@pu.edu.pk

1 Department of Botany, Faculty of Life Sciences, Quaid-e-Azam Campus, University of the Punjab, Lahore, Pakistan

2 Department of Botany, University of Veterinary and Animal Sciences, Pattoki, Pakistan with P. brasiliense (JF439492). Studied taxon was found conspecific with $P$. brasiliense in phylogenetic tree clustering with specimens collected from Indian Ocean (MH183258), South Korea (KM520128) and China (MH305508) with strong bootstrap support. To prove pathogenicity, 10 seedlings of healthy $S$. saligna plants were sprayed with $50 \mu \mathrm{l}$ conidial suspension of the fungus $\left(10^{7}\right.$ conidia/ml, $10 \mathrm{ml} /$ plant). Five control plants were treated with sterile distilled water. All plants were maintained at $15 \pm 5^{\circ} \mathrm{C}$, with $90 \%$ humidity. Characteristic leaf spots were evident 4 weeks post-inoculation on leaves, and $P$. brasiliense was consistently reisolated from all inoculated plants. No symptoms were observed on control plants. $P$. brasiliense has previously been reported from China on Acer truncatum; from Brazil on Coffea arabica, Phoradendron perrottettii and Tapirira guianensis; from Italy on Magnolia sp.; from South Africa on Prunus persica, P. salicina and from Spain on Vitis vinifera, respectively (Farr and Rossman 2019). To the best of our knowledge, this is the new record in Pakistan.

\section{References}

Farr DF, Rossman AY (2019) Fungal Databases, U.S. National Fungus Collections, ARS, USDA. Retrieved April 4, 2019, from https://nt. ars-grin.gov/fungaldatabases/

Ghayur MN, Gilani AH (2006) Studies on cardio-suppressant, vasodilator and tracheal relaxant effects of Sarcococca saligna. Arch Pharm Res 29(11):990-997

White TJ, Bruns T, Lee S, Taylor JW (1990) Amplification and direct sequencing of fungal ribosomal RNA genes for phylogenetics. In: Innis MA, Gelfand DH, Sninsky JJ, White TJ (eds) PCR protocols: a guide to methods and applications. Academic Press, San Diego, pp 315-332

Publisher's note Springer Nature remains neutral with regard to jurisdictional claims in published maps and institutional affiliations. 